\title{
Análise de trilha em caracteres produtivos de Pennisetum sob corte em Itambé, Pernambuco ${ }^{1}$
}

\author{
Mônica Alixandrina da Silva ${ }^{2}$, Mario de Andrade Lira ${ }^{3}$, Mércia Virgínia Ferreira dos Santos ${ }^{4}$, \\ José Carlos Batista Dubeux Junior ${ }^{4}$, Márcio Vieira da Cunha ${ }^{5}$, Erinaldo Viana de Freitas ${ }^{5}$
}

\footnotetext{
1 Trabalho financiado pelo PROMATA-CNPq.

2 Doutoranda em Zootecnia - UFRPE.

3 IPA, bolsista do CNPq.

${ }^{4}$ Departamento de Zootecnia - UFRPE. Bolsista do CNPq.

5 IPA.
}

RESUMO - Objetivou-se obter estimativas de coeficientes de correlação genética e avaliar os desdobramentos das correlações em efeitos diretos e indiretos (análise de trilha) das variáveis independentes explicativas sobre a produção de matéria seca (variável dependente principal) em cinco clones de capim-elefante. Foram realizados cinco cortes a cada 60 dias nas condições edafoclimáticas da Zona da Mata de Pernambuco. Cada parcela experimental apresentou $24 \mathrm{~m}^{2}$, com $2 \mathrm{~m}^{2}$ de área útil. Houve alta correlação entre quase todas as variáveis explicativas e a variável principal. Entretanto, a característica número de lâminas foliares por perfilho explicou melhor o potencial de produção de matéria seca e atuou de forma direta e indireta sobre as variáveis explicativas.

Palavras-chave: capineira, correlação, matéria seca, melhoramento

\section{Path analysis in productive characters of Pennisetum under cut in Itambé-PE}

\begin{abstract}
This work aimed to estimate the correlation coefficients, determining the direct and indirect effects (path analysis) of explanatory independent variables on total dry matter production (main dependent variables) of five elephant grass clones in five cuts accomplished at the forest zone of Pernambuco. Each experimental plot measured $24 \mathrm{~m}^{2}$ with $2 \mathrm{~m}^{2}$ of utile area. There was high correlation between almost all the independent variables and the main variable. The characteristic leaf blade number per tiller, however, explained better the potential of dry matter production and leaf blade dry matter production, acting, respectively, in a direct and indirect way on the explanatory variables.
\end{abstract}

Key Words: breeding, correlation, dry matter, forage bank

\section{Introdução}

Um dos objetivos básicos dos programas de melhoramento de gramíneas é a obtenção de genótipos mais produtivos. A produtividade é um caráter complexo e resultante da expressão e associação de diferentes componentes (Carvalho et al., 2002). Com a participação dos efeitos do ambiente na manifestação fenotípica, qualquer mecanismo que auxilie o pesquisador a conhecer os efeitos que interagem no comportamento de um caráter permite maior eficiência em sua seleção (Kurek et al., 2001).

Desta forma, a correlação entre caracteres no melhoramento genético é importante porque permite avaliar o quanto da alteração de um caráter pode afetar os demais no decurso da seleção. O conhecimento da magnitude e do valor das correlações, contudo, não são suficientes para esclarecer as relações entre as variáveis estudadas. Nesse contexto, a análise de trilha, "Path analysis", é um artifício utilizado por melhoristas para entender as causas envolvidas nas associações entre caracteres e decompor as correlações em efeitos diretos e indiretos (Cruz \& Regazzi, 1997).

No melhoramento de plantas, diversos trabalhos (Carvalho et al., 1999; Kurek et al., 2001; Carvalho et al., 2002; Montagner et al., 2004) têm sido desenvolvidos com o apoio dessa análise e são de grande significância na formulação de procedimentos apropriados para a seleção.

No capim-elefante (Pennisetum purpureum Schum.), contudo, os estudos ainda são restritos. Entretanto, por ser uma gramínea com alta capacidade produtiva, o conhecimento das inter-relações entre os caracteres de produção é de grande importância para que se possa conduzir com 
sucesso um programa de melhoramento visando à elevação do rendimento.

O potencial de produção de matéria seca do capimelefante é considerado elevado (Carvalho, 1985; Bose \& Morales, 1972) em relação às outras gramíneas forrageiras.

Nesse trabalho, realizou-se um estudo de correlação genética e fenotípica e do uso da análise de trilha em genótipos de Pennisetum sp. com o objetivo de verificar os efeitos de caracteres morfológicos sobre a produção de matéria seca.

\section{Material e Métodos}

O experimento foi realizado na Estação Experimental de Itambé, pertencente à Empresa Pernambucana de Pesquisa Agropecuária - IPA, localizada no município de Itambé, na microrregião fisiográfica da Mata Seca do estado de Pernambuco $\left(07^{\circ} 25^{\prime} 00^{\prime \prime S}, 35^{\circ} 06^{\prime} 00^{\prime \prime}\right.$ SWGr e altitude de $190 \mathrm{~m}$ ). No período de agosto de 2005 a agosto de 2006, a precipitação pluvial anual na microrregião é em torno de $1.300 \mathrm{~mm}$ (70\% desse total ocorre nos meses de março e julho) e a temperatura média anual é de $25,1^{\circ} \mathrm{C}$ (Figura 1). O clima é classificado como do tipo subúmido megatérmico (Anuário Estatístico de Pernambuco, 1991; Thornthwaite \& Matter, 1995).

Considerando o perfil de 0 a $20 \mathrm{~cm}$, o solo da área experimental foi classificado como franco-arenoso (18\% de argila) e apresentou densidade aparente de $1,1 \mathrm{~g} \mathrm{~cm}^{-3}$. Considerando o mesmo perfil (0 a $20 \mathrm{~cm})$, a análise das características químicas comprovou o seguinte resultado: pH (em água) = 5,5; P = 5 ppm; matéria orgânica = 2,8 \%; $\mathrm{Ca}^{++}=3,3(100 \mathrm{~cm})^{-3}$ de solo; $\mathrm{Mg}^{++}=1,4(100 \mathrm{~cm})^{-3}$ de solo; $\mathrm{Na}^{++}=0,05(100 \mathrm{~cm})^{-3}$ de solo; $\mathrm{K}^{+}=0,2(100 \mathrm{~cm})^{-3}$ de solo; $\mathrm{Al}^{+3}=0,2(100 \mathrm{~cm})^{-3}$ de solo; $\mathrm{H}^{+}=6,5(100 \mathrm{~cm})^{-3}$ de solo; $\mathrm{S}=5,0(100 \mathrm{~cm})^{-3}$ de solo; $\mathrm{CTC}=11,8(100 \mathrm{~cm})^{-3}$ de solo; $\mathrm{V}=44 \%, \mathrm{~m}=3,8 \%$. Após o corte de uniformização, efetuou-se adubação de cobertura com $\mathrm{K}_{2} \mathrm{O}$ (60 kg/ha), $\mathrm{N}$ (50 kg/ha) e $\mathrm{P}_{2} \mathrm{O}_{5}(100 \mathrm{~kg} / \mathrm{ha})$.

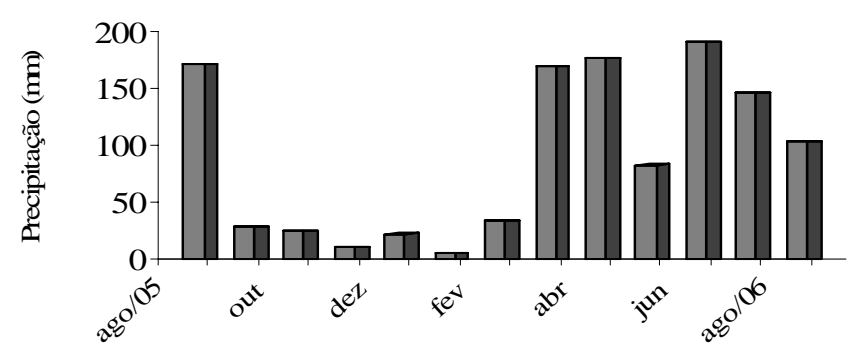

Figura 1 - Precipitação mensal durante o período experimental, Itambé, Pernambuco.
Os tratamentos experimentais foram compostos dos clones de Pennisetum sp. IRI 381, Venezuela A.D., Hexaplóide (híbrido), Elefante B e HV-241 (híbrido), avaliados durante cinco cortes. Os cortes foram realizados a cada 60 dias, rente ao solo, em uma área útil de $2 \mathrm{~m}^{2}$ utilizando-se um quadrado de $1 \mathrm{~m}^{2}$, considerando duas amostras sistemáticas. Utilizou-se para análise de variância delineamento em blocos casualizados.

Com base na ocorrência de multicolinearidade fraca entre as variáveis, ou seja, número de condição menor que 100 (Cruz \& Regazzi, 1997), foram utilizados na análise de trilha cinco caracteres: altura média da planta (AP), em metros, avaliada por meio de régua graduada, colocada no nível do solo até o ponto de curvatura da última lâmina; número de perfilhos basais $/ \mathrm{m}^{2}$ (NPB); produção de matéria seca (PMS), em $t$ de MS/ha, estimada por meio do peso do material existente dentro do quadrado multiplicado por seu teor de matéria seca e extrapolado para hectare; número de lâminas foliares por perfilho (NFP), obtido pela retirada e contagem das lâminas foliares; e relação folha/caule (RFC), calculada por meio da pesagem das lâminas e dos colmos de uma amostra da área colhida.

Para o estudo do efeito das variáveis na análise de trilha, considerou-se variável dependente principal a PMS. Como variáveis independentes explicativas, foram utilizados os caracteres AP, NFP, NPB e RFC. A interpretação do resultado da análise de trilha foi feita conforme recomendações de Singh \& Chaudary (1979), citados por Vencovsky \& Barriga (1992). Os coeficientes de correlação genotípica e fenotípica dos cinco caracteres estudados foram testados pelo método Bootstrap, com 5.000 simulações. As análises de variância, de correlação e de trilha foram realizadas por meio do programa computacional Genes (Cruz, 2001).

\section{Resultados e Discussão}

A análise conjunta dos dados comprovou diferenças significativas entre clones de Pennisetum para as variáveis altura da planta, número de perfilhos e número de lâminas foliares por perfilhos, no entanto, as variáveis produção de matéria seca e relação folha/caule não diferiram significativamente entre os clones. Esses resultados foram semelhantes aos encontrados por diversos autores para este tipo de avaliação (Botrel et al., 2000; Santos et al., 2001; Freitas et al., 2003).

Apesar da ausência de significância, o clone que apresentou maior produção de matéria seca foi o IRI 381, com média de 5,2 t/ha/corte, e o clone com menor produção foi o Hexaplóide, com 2,9 t/ha/corte. 
Os clones HV-241, Hexaplóide, Venezuela, Elefante B e IRI 381 apresentaram número de lâminas foliares por perfilho de 8, 7, 9, 7 e 9, respectivamente. Considerando o maior número de lâminas foliares por perfilho, pode-se indicar o clone IRI 381 para maior produção nas condições da Zona da Mata de Pernambuco. A altura dos clones HV-241, Hexaplóide, Venezuela, Elefante A e IRI 381 apresentam valores de 1,$06 ; 1,02 ; 1,32 ; 1,12$ e 1,30 , respectivamente, evidenciando que, neste estudo, o IRI 381 apresentou alta produção de matéria seca e uma das mais altas alturas e maior número de lâminas foliares por perfilhos, com baixo coeficiente de variação (Tabela 1).

O maior coeficiente de variação foi encontrado para produção de matéria seca (31,61\%) e o menor, para número de lâminas foliares por perfilho (10,0\%). O elevado coeficiente de variação de produção de matéria seca, também obtido em condições similares por Carvalho et al. (2002), está relacionado à utilização de parcelas de covas com plantas individuais, uma característica de experimentos genéticos com elevado número de grau de liberdade para tratamentos (Toledo, 1993). No entanto, a precisão experimental pode ser considerada adequada, em virtude da significância dos efeitos testados e de suas interações.

As correlações genotípicas de PMS com AP, NP, NFP E RFC foram geralmente superiores às fenotípicas (Tabelas 2 e 3), no entanto, NP mostrou correlações fenotípicas com PMS maiores que as genotípicas.
Esses resultados indicam interação diferenciada do ambiente sobre as relações de PMS com os demais caracteres. Quando as magnitudes das correlações não são semelhantes, as correlações genotípicas são intrinsecamente mais úteis que as fenotípicas para indicar estratégias de seleção (Kang et al., 1983).

Contudo, caracteres genotipicamente correlacionados, mas não fenotipicamente correlacionados, podem não ser de valor prático na seleção, que geralmente é baseada no fenótipo (Shukla et al., 1998). Assim, os dois tipos de correlação foram considerados neste estudo para facilitar a decisão sobre a eficiência de um critério de seleção indireta.

As variáveis AP e NFP apresentaram correlações fenotípicas positivas e significativas com a PMS de clones de Pennisetum (Tabela 2), demonstrando que essas variáveis influenciam a expressão dessas características. O mesmo comportamento foi observado para a correlação genotípica (Tabela 3), porém, nesta correlação o NP foi a variável que não apresentou significância com a produção de MS.

Segundo Montardo et al. (2003), uma possível razão para baixa correlação entre variáveis seria a ocorrência de pouca variabilidade em uma das variáveis, uma vez que a análise de trilha identifica uma eventual associação na variação das características em estudo.

Entre as variáveis correlacionadas fenotipicamente e genotipicamente com a PMS, a relação lâmina foliar/colmo e o número de perfilhos basais foram as que evidenciaram tendência de valor negativo, o que implica correlação de

Tabela 1 - Resumo da análise de variância para os caracteres morfológicos de clones de Pennisetum sob corte

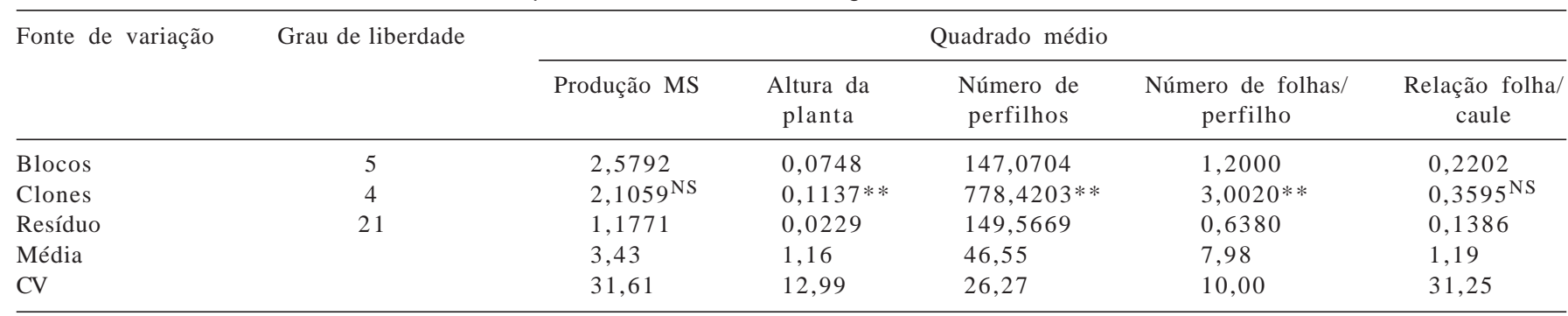

** Significativo a $1 \%$ de probabilidade pelo teste $\mathrm{F}$.

NS Não-significativo pelo teste F.

Tabela 2 - Correlações fenotípicas entre as características avaliadas

\begin{tabular}{lccccc}
\hline & Produção MS & Altura da planta & Número de perfilhos & Número de folhas/perfilho & Relação folha/caule \\
\hline Produção de matéria seca & - & $0,912 * *$ & $-0,553^{*}$ & $0,823^{* *}$ & $-0,772^{* *}$ \\
Altura da planta & - & $-0,606^{*}$ & $0,900^{* *}$ & $-0,878^{*}$ \\
Número de perfilhos basais & & - & $-0,568^{*}$ & - \\
Número de folhas/perfilho & & & - & $-0,774^{* *}$ \\
Relação folha/caule & & & - \\
\hline
\end{tabular}

**,*Significativo a 5 e 1\%, respectivamente, pelo método de bootstrap com 5.000 simulações. 
Tabela 3 - Correlações genotípicas entre as características avaliadas

\begin{tabular}{lccccc}
\hline & Produção MS & Altura da planta & Número de perfilhos & Número de folhas/perfilho Relação folha/caule \\
\hline Produção de matéria seca & - & $1,000^{* *}$ & $-0,4859$ & $1,000^{* *}$ \\
Altura da planta & - & $-0,6362$ & $1,000^{* *}$ & $-1,000^{* *}$ \\
Número de perfilhos basais & & $-0,7954$ & $-1,000 * *$ \\
Número de folhas/perfilho & & & & $-1,000^{* *}$ \\
Relação folha/caule & & & $-1,000^{* *}$ \\
\hline
\end{tabular}

**, ${ }^{*}$ Significativo a $1 \%$, respectivamente, pelo método de bootstrap com 5.000 simulações.

caracteres de sentido contrário, em que o aumento de um corresponde à diminuição do outro. A relação lâmina foliar/ colmo apresentou correlação positiva apenas com o NP (Tabelas 2 e 3).

Além da correlação genotípica positiva com a produção de matéria seca, a altura da planta também apresentou alta correlação positiva e significativa com o número de lâminas foliares por perfilho, indicando que plantas mais altas são mais produtivas e também apresentam maior número de folhas (Tabela 3).

O número de perfilhos foi a variável que apresentou correlação genotípica e fenotípica negativa com a maioria das variáveis, com exceção da relação folha/caule. Esses resultados indicam que, quanto mais a planta perfilhar, menor a altura da planta e maior a relação folha/caule.

A altura da planta, o número de lâminas foliares por perfilho, o número de perfilhos e a relação folha/colmo apresentaram altas correlações genotípicas entre si. Pode-se inferir que ocorre um sistema de inter-relações entre essas características e, por meio deste sistema, determinada variável poderia interferir na produção de matéria seca por meio de outra característica correlacionada.

A altura da planta apresentou alta correlação genotípica com a produção de matéria seca, porém, essa correlação se deveu muito pouco ao seu efeito direto e foi promovida, basicamente, pelo efeito indireto do número de lâminas foliares por perfilho. A correlação positiva entre essas duas variáveis está relacionada, indiretamente, ao efeito do número de lâminas foliares por perfilhos (Tabela 4), importante no processo de crescimento da planta.

Ressalta-se que a unidade de crescimento da gramínea é o fitômero, composto de lâmina foliar, bainha, entrenó, nó e gema. Durante o desenvolvimento inicial da gramínea, ocorre a formação de fitômeros sucessivos, nos quais o crescimento mais intenso é o das folhas (Gomide et al., 2003). Assim, a lâmina foliar é um dos constituintes de maior importância no processo de crescimento da planta.

Uma vez que a síntese de folhas é a primeira no processo de formação da planta (Woledge, 1978), é possível que o número de lâminas foliares por perfilho influencie a altura da planta, que só começa seu crescimento quando a planta necessita que o colmo se alongue para a formação de novas folhas. Assim, o número de lâminas foliares por perfilho contribui para o aumento da altura da planta.

Muitos autores consideram apenas a correlação como instrumento para medir a influência da altura da planta sobre a produção de matéria seca (Santos et al., 1994; Lira et al., 1999; Mello et al., 2002; Teixeira et al., 2003). Segundo esses autores, esta variável é de boa confiabilidade e deve ser considerada para estimar a produção de matéria seca total. Nesta pesquisa, por sua baixa influência em efeito direto (Tabela 4), a altura da planta teve baixo efeito indireto nas variáveis estudadas.

Os resultados deste trabalho estão de acordo com relatos de Daher et al. (2004), que observaram efeitos semelhantes da altura da planta, que apresentou baixo efeito direto sobre a produção de matéria seca, reduzindo sua importância em relação às demais variáveis.

O número de perfilhos basais teve efeito direto positivo sobre a produção de matéria seca (Tabela 4). Neste caso, os efeitos indiretos negativos apresentaram forte influência no efeito direto do número de perfilhos basais, interferindo na correlação negativa desta variável com a produção de matéria seca (Tabelas 2 e 3).

Diversos autores afirmam que o número de perfilhos é uma variável que influencia a produção de matéria seca (Andrade et al., 2003; Alexandrino et al., 2005; Fagundes et al., 2005). Neste estudo, o caráter número de perfilhos teve pouca importância no aspecto da seleção. Os clones em estudo sofreram estresse hídrico, o que ocasionou em determinados cortes aumento da densidade populacional dos perfilhos, porém sem crescimento, resultando em perfilhos menos pesados, com menor número de fitômeros.

Na seleção de plantas forrageiras, a manipulação da dinâmica do perfilhamento pode ser uma importante estratégia para o manejo da pastagem, principalmente porque a densidade populacional de perfilhos é determinante da perenidade e persistência do pasto (Freitas et al., 2003; Fagundes et al., 2005; Carvalho et al., 2006). No caso de capineiras, o perfilhamento, notadamente basal, possibilita a rebrota após o corte. 
Tabela 4 - Desdobramento das correlações genotípicas de caracteres de Pennisetum sp. sob corte em efeitos direto e indireto sobre a produção de matéria seca total (t de MS/ha) pela análise de trilha

Caracter

Altura da planta

$\begin{array}{lr}\text { Efeito direto sobre PMS } & 0,1639 \\ \text { Efeito indireto via NPB } & -0,5322 \\ \text { Efeito indireto via RFC } & 0,0373 \\ \text { Efeito indireto via NFP } & 1,6017 \\ \text { Total }\end{array}$

0,1639

0,0373

, 6017

Total

$1,0000 * *$

Número de perfilhos basais

$\begin{array}{lr}\text { Efeito direto sobre PMS } & 0,8366 \\ \text { Efeito indireto via RFC } & -0,0356 \\ \text { Efeito indireto via NFP } & -1,1825 \\ \text { Efeito indireto via AP } & -0,1043\end{array}$

Total

Número de lâminas foliares/perfilhos

$\begin{array}{lr}\text { Efeito direto sobre PMS } & 1,4867 \\ \text { Efeito indireto via NPB } & -0,6654 \\ \text { Efeito indireto via RFC } & 0,0394 \\ \text { Efeito indireto via AP } & 0,1766\end{array}$

Total

$1,0000 * *$

Relação folha/colmo

$\begin{array}{lr}\text { Efeito direto sobre PMST } & -0,0329 \\ \text { Efeito indireto via NPB } & 0,9058 \\ \text { Efeito indireto via NFP } & -1,7761 \\ \text { Efeito indireto via AP } & -0,1855\end{array}$

Total

$-1,0000 * *$

Coeficiente de determinação

1.0000

Efeito da variável residual

10.000

ns não-siginificativo pelo método de bootstrap com 5.000 simulações.

${ }^{* *}$ significativo pelo método de bootstrap com 5.000 simulações a 1\%.

O número de lâminas foliares por perfilho apresentou efeito direto alto sobre a produção de matéria seca, indicando sua verdadeira correlação com essa variável dependente e não sofrendo um alto efeito indireto das demais variáveis estudadas, exceto do número de perfilhos (Tabela 4). Ressaltar que a correlação entre essas duas características decorreu praticamente apenas do efeito direto do número de lâminas foliares por perfilho sobre a produção de matéria seca. Apesar de a correlação genotípica (Tabela 3) entre o número de lâminas foliares por perfilho e a variável altura da planta $(1,000)$ e a relação folha/caule $(-1,000)$ serem consideradas altas, estas variáveis pouco influenciaram o efeito direto do número de lâminas foliares por perfilho sobre a produção de matéria seca (Tabela 3). Desta forma, variáveis com altas correlações entre si não necessariamente apresentam efeitos indiretos altos sobre as outras. Estes efeitos serão conseqüências das condições genéticas da planta e do ambiente. Uma possível causa para que a altura da planta não tenha apresentado efeito indireto sobre o número de lâminas foliares por perfilho, pode ter sido o estresse hídrico sofrido pelos clones, alterando seu comportamento nos meses de baixa precipitação (Figura 1).

Em um processo de seleção para aumentar apenas a produção de matéria seca, o número de lâminas foliares por perfilho foi como a principal característica nesta determinação, indicando que uma forte pressão de seleção desse caráter irá beneficiar a produção. Quando se trabalha com forrageira de corte, é importante observar o rendimento total da planta. Entretanto, deve-se considerar a importância das lâminas foliares em termos qualitativos. Assim, o número de lâminas foliares por perfilho também deve ser considerado no processo de seleção para aumento da qualidade.

Neste trabalho observou-se uma correlação genotípica negativa entre o número de lâminas foliares/perfilho e a relação folha/colmo (Tabela 3), comprovando que, quanto maior o número de lâminas foliares, menor será o peso dessas lâminas. Paciullo et al. (2003), trabalhando com morfogênese de capim-elefante, relataram que a taxa de aparecimento de folhas é inversamente correlacionada ao 
tamanho final da folha, e que folhas menores são conseqüência do aumento na taxa de aparecimento.

A relação folha/colmo apresentou um dos menores efeitos diretos sobre a produção de matéria seca (Tabela 4) e não sofreu influência indireta positiva de outros caracteres, exceto o número de perfilhos. Neste caso, os efeitos indiretos negativos tiveram forte influência no efeito direto da relação folha/colmo, o que interfere na correlação negativa desta variável com a produção.

No caso da produção de matéria seca, ao isolar-se os efeitos indiretos da relação folha/colmo, ter-se-ia uma fraca correlação de sentido negativo. Desta forma, a relação lâmina foliar/colmo não contribui com a produção de matéria seca, o que contraria diversas afirmações (Mello et al., 2002; Brâncio et al., 2003; Alexandrino et al., 2005) de que a relação folha/colmo tem correlação positiva com a produção de matéria seca. Entretanto, Candido et al. (2005) concordam que a altura da planta influencia a produção de matéria seca, mas diminui a relação folha/colmo (Tabela 3).

\section{Conclusões}

Em programas de melhoramento de Pennisetum sp. sob corte visando aumento na produção de matéria seca, deve-se priorizar a seleção de genótipos com maior número de lâminas foliares por perfilho. A análise de trilha mostrou-se um procedimento útil e de fácil aplicação no detalhamento das correlações entre as variáveis estudadas.

\section{Literatura Citada}

ALEXANDRINO, E.; GOMIDE, J.A.; GOMIDE, C.A.M. Crescimento e desenvolvimento do dossel de Panicum maximum Cv. Mombaça. Revista Brasileira de Zootecnia, v.34, n.6S, p.2164-2173, 2005.

ANDRADE, J.B.; FERRARI JR., E; POSSENTI, R.A. et al. Produção e composição de genótipos de cana-de-açúcar. Boletim da Indústria Animal, v.60, n.1, p.11-22, 2003.

ANUÁRIO ESTATÍSTICO DE PERNAMBUCO. Recife: IBGE, 1991. v. 40.

BOSE, M.L.V.; MORALES, C.L. Composição em fibra bruta, celulose e lignina, digestibilidade da celulose in vitro e em C. E. D. de algumas gramíneas em desenvolvimento vegetativo. O Solo, Piracicaba, v.64, n.1, p.49-56, 1972.

BOTREL, M.A.; PEREIRA, A.V.; FREITAS, V.P. et al. Potencial forrageiro de novos clones de capim elefante. Revista Brasileira de Zootecnia, v.29, n.2 p.334-340, 2000.

BRÂNCIO, P.A.; EUCLIDES, V.P.B.; NASCIMENTO JR., D. et al. Avaliação de três cultivares de Panicum maximum Jacq. sob pastejo: disponibilidade de forragem, altura do resíduo póspastejo e participação de folhas, colmos e material morto. Revista Brasileira de Zootecnia, v.32, n.1, p.55-63, 2003.

CANDIDO, M.J.D.; GOMIDE, C.A.M.; ALEXANDRINO, E. et al. Morfofisiológia do dossel de Panicum maximum cv. Mombaça sob lotação intermitente com três períodos de descanso. Revista Brasileira de Zootecnia, v.34, n.2, p.406-415, 2005.
CARVALHO, L.A. Pennisetum purpureum Schumacher: Revisão. Coronel Pacheco: EMBRAPA-CNPGL, 1985. 86p. (EMBRAPACNPGL, Boletim de Pesquisa, 10).

CARVALHO, C.G.P.; OLIVEIRA, M.F.; CRUZ, C.D. et al. Análise de trilha sob multicolinearidade em pimentão. Pesquisa Agropecuária Brasileira, v.34, n.4, p.603-613, 1999.

CARVALHO, C.G.P.; ARIAS, C.A.A.; TOLEDO, J.F.F. et al. Correlação e análise de trilha em linhagens de soja semeadas em diferentes épocas. Pesquisa Agropecuária Brasileira, v.37, n.3, p.311-320, 2002.

CARVALHO, C.A.B.; PACIULLO, D.S.C.; ROSSIELLO, R.O.P. et al. Dinâmica do perfilhamento em capim elefante sob influência da altura do resíduo pós-pastejo. Pesquisa Agropecuária Brasileira, v.41, n.1, p.145-152, 2006

CRUZ, C.D. Programa Genes-versão Windows: aplicativo computacional em genética e estatística. Viçosa, MG: Universidade Federal de Viçosa, 2001. (CD-ROM).

CRUZ, C.D.; REGAZZI, A.J. Modelos biométricos aplicados ao melhoramento genético. Viçosa, MG: Universidade Federal de Viçosa, 1997. 390p.

DAHER, R.F.; PEREIRA, A.V.; PEREIRA, M.G. et al. Análise de trilha de caracteres forrageiros do capim-efefante (Pennisetum purpureum Schum.). Ciência Rural, v.34, n.5, 2004.

FAGUNDES, J.L.; FONSECA, D.M.; MISTURA, C. et al. Índice de área foliar, densidade de perfilhos e acúmulo de forragem em pastagem de capim-braquiária adubada com nitrogênio. Boletim da Indústria Animal, v.62, n.2, p.125-133, 2005.

FREITAS, E.V.; LIRA, M.A.; DUBEUX JR., J.C.B. et al. Caracteres morfofisiológicos de clones de capim elefante (Pennisetum purpureum, Shum) avaliados sob pastejo intensivo na Zonada-Mata de Pernambuco. Boletim da Industria Animal, v.60, n.2, p.127-138, 2003.

GOMIDE, C.A.M.; GOMIDE, J.A.; ALEXANDRINO, E. Índices morfogênicos e de crescimento durante o estabelecimento e a rebrotação do capim-mombaça (Panicum maximum Jacq.). Revista Brasileira de Zootecnia, v.32, n.4, p.795-803, 2003.

KANG, M. S.; MILLER, J.D.; TAI, P.Y.P. Genetic and phenotypic path analyses and heritability in sugarcane. Crop Science, v.23, n.4, p.643-647, 1983.

KUREK, A.J.; CARVALHO, F.I.F; ASSMANN, I.C. et al. Análise de trilha como critério de seleção indireta para rendimento de grãos em feijão. Revista Brasileira de Agrociência, v.7, n.1, p.29-32, 2001

LIRA, M.A.; DUBEUX JR., J.C.B; OLIVEIRA, C.F. et al. Competição de cultivares de capim elefante (Pennisetum purpureum, schum) e de híbridos de capim-elefante x milheto (Pennisetum americanum (L.) leeke) sob pastejo. Revista Brasileira de Zootecnia, v.28, n.5, p.936-946, 1999.

MELLO, A.C.L.; LIRA, M.A.; DUBEUX JR., J.C.B. et al. Caracterização e seleção de clones de capim-elefante (Pennisetum purpureum, Schum.) na Zona da Mata de Pernambuco. Revista Brasileira de Zootecnia, v.31, n.1, p.30-42, 2002.

MONTARDO, D.P.; DALL'AGNOL, M.; CRUSIUS, A.F. et al. Análise de trilha para rendimento de sementes de trevo vermelho (Trifolium pratense L.) Revista Brasileira de Zootecnia, v.32, n.5, p.1076-1082, 2003.

MONTAGNER, D.; LOVATO, C.; GARCIA, D.C. Perdas aleatórias na população inicial e sua relação com o rendimento de grãos em sorgo. Revista Brasileira de Agrociência, v.10, n.3, p.281-285, 2004.

PACIULlO, D.S.C.; DERESZ, F.; AROEIRA, L.J.M. et al. Morfogênese e acúmulo de biomassa foliar em pastagem de capim elefante avaliada em diferentes épocas do ano. Pesquisa Agropecuária Brasileira, v.38, n.7, p.881-887, 2003.

SANTOS, E.A.; SILVA, D.S.; QUEIROZ FILHO, J.L. Perfilhamento e algumas características do capim-elefante cv. Roxo sob quatro alturas de corte em duas épocas do ano. Revista Brasileira de Zootecnia, v.30, n.1, p.24-30, 2001. 
SANTOS, M.C.S.; TABOSA, J.N.; DIAS, F.M. et al. Comportamento de clones de capim elefante e de híbridos de capim elefante $\mathrm{x}$ milheto no semi-árido do nordeste do Brasil. Pesquisa Agropecuária Brasileira, v.29, n.10, p.1609-1615, 1994.

SHUKLA, S.; SINGH, K.; PUSHPENDRA. Correlation and path coefficient analysis of yield and its components in soybean (Glycine $\max$ L. Merrill.). Soybean Genetics Newsletter, v.25, p.67-70, 1998.

TEIXEIRA, F.V.; CAMPOS, O.F.; CÓSER, A.C. Uso dos índices altura da planta e cobertura do solo e da associação dessas variáveis para estimativa da forragem disponível em pastagem de capim elefante. Revista Universidade Rural, v.22, n.2, p.15-22, 2003.
THORNTHWAITE, C.W.; MATTER, J.R. The water oudget and its use irrigation. In: THORNITHWAITE, C.W.; MATTER, J.R. (Eds.) Water the year book of agriculture. Washington: USDA, 1995. p.356-358.

TOLEDO, J.F.F. Genética quantitativa das características de interesse do melhoramento da soja (Resultados de pesquisa de soja 1989/90). Londrina: Embrapa Centro Nacional de Pesquisa de Soja, 1993. p.260-264. (Documentos, 58).

VENCOVSKY, R.; BARRIGA, P. Genética biométrica no fitomelhoramento. Ribeirão Preto: Revista Brasileira de Genética, 1992. 496p.

WOLEDGE, J. The effect of shading during vegetative and reproductive growth on the photosynthetic capacity of leaves in a grass sward. Annals of Botany, v.42, p.1085-1089, 1978. 